\title{
HUBUNGAN INDEKS MASSA TUBUH (IMT) DAN KONSUMSI MAKANAN JUNK FOOD DENGAN USIA MENARCHE PADA SISWI SMP BINA CIPTA PALEMBANG TAHUN 2019
}

\author{
Sri Emilda \\ Program Studi D III Kebidanan STIKES Mitra Adiguna Palembang \\ Komplek Kenten Permai Blok J No. 9-12 Bukit Sangkal Palembang 30114 \\ Email : sriemilda1@gmail.com
}

\begin{abstract}
Abstrak
Menstruasi adalah proses alamiah yang terjadi pada perempuan. Menstruasi merupakan perdarahan yang teratur dari uterus sebagai tanda bahwa organ kandungan telah berfungsi matang. Umumnya remaja yang mengalami menarche adalah pada usia 12 sampai dengan 16 tahun. Tujuan penelitian ini adalah Diketahui hubungan Indeks Massa Tubuh (IMT) dan konsumsi makanan junk fooddengan usia menarche pada siswi SMP Bina Cipta Palembang tahun 2018. Penelitian ini menggunakan metode analitik dengan pendekatan cross sectional. Populasi pada penelitian ini adalah semua siswi kelas VII dan VIII SMP Bina Cipta Palembang dengan jumlah sampel sebanyak 58 responden. Hasil penelitian didapatkan ada hubungan Indeks Massa Tubuh (IMT) dengan usia menarche pada siswi SMP Bina Cipta Palembang tahun 2018 dengan nilai $p$ value 0,006 $<\alpha(0,05)$ dan OR= 6,563. Ada hubungan konsumsi makanan junk food dengan usia menarche pada siswi SMP Bina Cipta Palembang tahun 2018 dengan nilai $p$ value $0,005<\alpha(0,05)$ dan $O R=6,545$. Kesimppulan ada hubungan Indeks Massa Tubuh (IMT) dan konsumsi makanan junk food dengan usia menarche pada siswi SMP Bina Cipta Palembang tahun 2018. Saran penelitian Peneliti menyarankan agar pihak sekolah dapat memberikan lebih banyak informasi untuk meningkatkan pengetahuan siswi tentang Indeks Massa Tubuh (IMT) dan konsumsi makanan junk food terhadap usia menarche serta memperbanyak melaksanakan kegiatan penyuluhan dengan mendatangkan nara sumber baik dokter maupun psikolog untuk berdiskusi tentang kesehatan reproduksi khususnya masalah menarche.
\end{abstract}

Kata Kunci : Indeks Massa Tubuh, Junk Food, Menarche

\begin{abstract}
Menstruation is a natural process that occurs in women. Menstruation is regular bleeding from the uterus as a sign that the uterine organs are functioning properly. Generally, adolescents who experience menarche are at the age of 12 to 16 years. The purpose of this study is to determine the relationship of Body Mass Index (BMI) and junk food consumption with the age of menarche in Bina Cipta Palembang Middle School students in 2018. This study uses analytical methods with cross sectional approach. The population in this study were all students of class VII and VIII Bina Cipta Palembang with a total sample of 58 respondents. The results showed that there was a relationship between Body Mass Index (BMI) and age of menarche in Bina Cipta Palembang Junior High School students in 2018 with a p value of 0.006 $<\alpha(0.05)$ and $O R=6.563$. There is a relationship of junk food consumption with the age of menarche in Bina Cipta Palembang Middle School students in 2018 with a $p$ value of $0.005<\alpha(0.05)$ and OR= 6.545. Conclusion there is a relationship between Body Mass Index (BMI) and junk food consumption with age of menarche in Bina Cipta Palembang Junior High School students in 2018. Research Suggestions Researchers suggest that schools can provide more information to increase student knowledge about Body Mass Index (BMI) and junk food consumption towards the age of menarche and increasing the number of counseling activities by bringing in resource persons both doctors and psychologists to discuss reproductive health, especially the problem of menarche.
\end{abstract}

Keywords : Body Mass Index, Junk Food, Menarche 


\section{PENDAHULUAN}

Perkembangan fisik pada remaja paling pesat diantara tahap-tahap perkembangan manusia. Padamasa ini terjadi pacu tumbuh berat badan dan tinggi badan, termasuk pertumbuhan tanda-tanda seks sekunder. Pesatnya perkembangan pada masa pubertas dipengaruhi oleh hormon seksual. Organorgan reproduksi padamasa puber telah mulai berfungsi. Salah satu cirimasa pubertas adalah mulai terjadinya menstruasi pada perempuan yang disebut dengan menarche yaitu menstruasi pertama kali (Proverawati dalam Diaris, 2017).

Menstruasi adalah proses alamiah yang terjadi pada perempuan. Menstruasi merupakan perdarahan yang teratur dari uterus sebagai tanda bahwa organ kandungan telah berfungsi matang. Umumnya remaja yang mengalami menarche adalah pada usia 12 sampai dengan 16 tahun. Periode ini akan mengubah perilaku dari beberapa aspek, misalnya psikologi dan lainnya. (Kusmiran, 2012).

Penurunan rata-rata usia menarche mulai diketahui pada awal abad ke-20. Terlihat pada beberapa penelitian di negaranegara industri benua Amerika dan Eropa dengan ditemukannya penurunan usia menarche sebesar 2-3 bulan tiap dekade dalam kurun waktu 100 sampai 500 tahun terakhir. Di Amerika Serikat, rata-rata usia menarche adalah lebih dari 14 tahun sebelum tahun 1900 dan antara tahun 1988 dan 1994 menurun menjadi 12,43 tahun. Di Benua Eropa, seperti di Portugis, Italia, Spanyol, Venezuela dan Inggris, umur ratarata menarche untuk remaja putri yang lahir di tahun 1880-1890 adalah 15,0 tahun dan menjadi 12,03 tahun untuk remaja putri yang lahir di tahun 1970-1980.(Putra, 2016).

Di Indonesia usia remaja pada waktu menarche bervariasi antara 10 sampai 16 tahun dan rata-rata menarche pada usia 12,5 tahun. Usia menarche lebih dini terjadi pada remaja yang tinggal di daerah perkotaan daripada remaja yang tinggal di daerah pedesaan. Hasil laporan Riset Kesehatan Dasar (Riskesdas) diketahui bahwa 20,9\% anak perempuan di Indonesia telah mengalami menarche di umur kurang dari 12 tahun (Fuadah, 2016).

Usia menarche yang terjadi terlalu lambat maupun terlalu cepat berdampak buruk bagi kesehatan. Remaja yang mengalami menarche dibawah usia 11,9 tahun dapat meningkatkan penyakit kardiovaskular. Sedangkan menarche yang terjadi terlambat dapat menyebabkan kegagalan dalam penimbunan mineral pada tulang. Dampak lain yaitu wanita yang mengalami menarche lebih cepat akan mengalami menopause lebih lambat dan wanita yang mengalami menarche lebih lambat akan mengalami menopause lebih cepat (Destur, 2012).

Data demografi menunjukan bahwa remaja merupakan populasi yang besar dari penduduk dunia. Menurut WHO (World Health Organization) sekitar seperlima dari penduduk dunia adalah remaja berumur 1019 tahun dan sekitar 900 juta berada di Negara sedang berkembang. Pada masa remaja manusia mengalami perkembangan yang pesat baik fisik, psikis maupun sosialnya terjadinya pertumbuhan yang pesat pada remaja disebabkan oleh perubahan kematangan fisiologi sehubungan dengan timbulnya pubertas (Depkes dalam Hardianingsih, 2017).

Berdasarkan data Kementrian Kesehatan Republik Indonesia (Kemenkes RI, 2017), jumlah penduduk Indonesia pada kategori usia 10-14 tahun sebanyak 22.577 .094 orang $(8,73 \%)$, sedangkan kategori usia 15-19 tahun sebanyak 22.160 .951 orang $(8,57 \%)$.

Sedangkan berdasarkan data Dinas Kesehatan Provinsi Sumatera Selatan, jumlah penduduk pada kategori usia 10-14 tahun sebanyak 765.601 orang $(9,61 \%)$ dan penduduk pada kategori usia 15-19 tahun sebanyak 763.129 orang $(9,58 \%)$ (Dinkes Prov.Sumatera Selatan, 2016). 
Berdasarkan data Dinas Kesehatan Kota Palembang, jumlah penduduk pada kategori usia 10-14 tahun sebanyak 133.248 orang $(8,43 \%)$ dan penduduk pada kategori usia 15-19 tahun sebanyak 155.144 orang (9,82\%) (Dinkes Kota Palembang, 2016).

Penurunan usia menarche dihubungkan karena beberapa faktor yang meliputi keadaan gizi, genetik, konsumsi makanan, hormon, sosial ekonomi, keterpaparan media massa orang dewasa (pornografi ), perilaku seksual dan gaya hidup. Gaya hidup merupakan kebiasaan sehari-hari yang dilakukan remaja putri yang berkaitan dengan olahraga, konsumsi soft drink dan makan makanan fast food (Soetjiningsih dalam Faudah, 2016).

Selama pubertas, asupan gizi dan perubahan hormon pada remaja sangat berpengaruh terhadap terjadi akselerasi pertumbuhan tinggi badan yang mendadak yang disebut pacu tumbuh. Pada remaja perempuan kecepatan pertumbuhan maksimal dicapai 6-12 bulan sebelum menarche. Pada remaja perempuan, saat memasuki masa pubertas berat badan mencapai kira-kira $60 \%$ berat dewasa. Mencapai puncak kecepatan berat badan sekitar 8 kg/tahun. (Proverawati dalam Diaris, 2017).

Perbaikan nutrisi dan kesehatan pada anak dan remaja dapat diketahui dari perhitungan nilai IMT (Indeks Massa Tubuh). IMT adalah hasil perhitungan dari perbandingan BB (Berat Badan) dan TB (Tinggi Badan) melalui rumus $\mathrm{BB} / \mathrm{TB} 2$ $(\mathrm{kg} / \mathrm{m} 2)$. Berdasarkan nilai kisarannya, IMT terbagi menjadi 3 kategori, yaitu : underweight $\quad(\mathrm{IMT} \leq 18,4), \quad$ normal (IMT=18,5-25), dan overweight (IMT $\geq 25,1) \quad$ (Soetjiningsih dalam Putra, 2016).

Usia menarche yang semakin dini telah dikaitkan dengan peningkatan IMT selama bertahun-tahun. Usia menarche yang lebih dini juga dialami oleh wanita dengan IMT berlebih (overweight) dibandingkan dengan yang normal atau kurus (underweight).
Tidak ditemukannya penurunan usia menarche pada anak dengan perawakan kurus (underweight) juga mendukung bukti IMT sebagai faktor terkuat penyebab penurunan usia menarche (Speroff dalam Putra, 2016).

Dengan terjadinya IMT yang tinggi, salah satunya dapat dikarenakan kandungan lemak berlebih kemudian lemak berlebih dalam tubuh memicu peningkatan pada adypocyte-derived hormone leptin. Adypocyte-derived hormone leptin yang kemudian memicu seksresi hipotalamus untuk melepaskan gonadotropin releasing hormone $(\mathrm{GnRH})$ yang kemudian menginduksi kelenjar hipofisis anterior untuk melepaskan luteinizing hormon (LH). Luteinizing hormon (LH) yang tinggi sehingga mengawali terjadinya menarche. Apabila hormon LH lebih dini di sekresikan maka akan semakin dini terjadinya menarche pada remaja. Begitu pula sebaliknya, apabila hormon tersebut semakin lama disekresikan, maka usia menarche semakin lama datangnya (Yuliastuti, 2015).

Ahli gizi mengungkapkan kebiasaan mengkonsumsi makanan fast food yang berlebihan kurang baik. Konsumsi fast food yang baik jika frekwensinya 1 kali dalam seminggu, jika lebih dari itu dikatakan tidak baik. Kebiassaan makan fast food yang berlebih dapat mengakibatkan obesitas pada anak (Achtung dalam Maidartati, 2013). Obesitas mempengaruhi tingkat kesuburan seorang perempuan sehingga anak yang mengalami obesitas kematangan seksualnya ditemukan lebih cepat meliputi pertumbuhan payudara, menarche, pertumbuhan rambut pubis serta aksila lebih cepat (Soetjiningsih dalam Maidartati, 2013).

Kebiasaan makan fast food merupakan perilaku seseorang dalam memenuhi kebutuhan makan sehari-hari, berupa konsumsi makanan meliputi jenis dan frekwensi asupan makanan yang berkalori tinggi seperti : pizza, fried chicken, kentang goreng, es kream dan aneka makanan mie. 
Konsumsi makanan fast food dikatakan baik jika frekwensinya 1 kali dalam seminggu, jika lebih dari itu dikatakan kurang baik karena berdampak pada kesehatan tubuh (Maidartati, 2013).

Berdasarkan hasil observasi yang peneliti lakukan terhadap 10 orang remaja putri di SMP Bina Cipta Palembang didapatkan bahwa 6 orang remaja putri mengalami menarche pada usia $<12$ tahun dan 4 orang yang menarche pada usia $>12$ tahun. Sebagian besar remaja putri mengatakan sering mengkonsumsi junk food.

Berdasarkan data siswa yang didapat dari SMP Bina Cipta Palembang, jumlah siswa kelas 7A sebanyak 42 orang (siwa putri sebanyak 24 orang dan siswa putra 18 sebanyak orang), kelas 7B sebanyak 40 orang (siswa putri sebanyak 20 orang dan siswa putra sebanyak 20 orang), kelas $8 \mathrm{~A}$ sebanyak 31 orang (siswa putri sebanyak 17 orang dan siswa putra sebanyak 14 orang), kelas $8 \mathrm{~B}$ sebanyak 31 orang (siswa putri sebanyak 18 orang dan siswa putra sebanyak 13 orang), kelas 9A sebanyak 31 orang (siswa putri sebanyak 14 orang dan siswa putra sebanyak 17 orang) dan kelas 9B sebanyak 30 orang (siswa putri sebanyak 11 orang dan siswa putra sebanyak 19 orang).

Berdasarkan data dan fakta diatas peneliti tertarik untuk melakukan penelitian dengan judul "Hubungan Indeks Massa Tubuh (IMT) dan Konsumsi Makanan Junk Food Dengan Usia Menarche Pada Siswi SMP Bina Cipta Palembang Tahun 2019".

\section{METODE PENELITIAN}

Penelitian adalah suatu upaya untuk memahami dan memecahkan masalah secara ilmiah, sistematis dan logis (Notoatmodjo, 2012).

Penelitian ini menggunakan metode analitik dengan pendekatan cross sectional. Metode analitik adalah penelitian yang mencoba menggali bagaimana fenomena kesehatan itu terjadi. Kemudian melakukan analisis dinamika korelasi antara fenomena antara faktor risiko (Indeks Massa Tubuh (IMT) dan konsumsi makanan junk food) dengan faktor efek (usia menarche). Sedangkan pendekatan cross sectional ialah suatu penelitian untuk mempelajari dinamika korelasi antara faktor-faktor resiko dengan efek, dengan cara pendekatan, observasi atau pengumpulan data sekaligus pada suatu saat (point time approach) (Notoatmodjo, 2012).

\section{Waktu dan Tempat Penelitian \\ Waktu Penelitian}

Penelitian ini dilaksanakan pada tanggal 4-5 April 2019.

\section{Tempat Penelitian}

Penelitian ini dilaksanakan di SMP Bina Cipta Palembang.

\section{Data dan Cara Pengumpulan Data Data Primer}

Dalam penelitian ini data primer diperoleh secara langsung dengan cara memberikan pertanyaan dalam bentuk kuesioner kepada siswi kelas VII dan VIII SMP Bina Cipta Palembang untuk mengetahui Indeks Massa Tubuh (IMT),konsumsi makanan junk food dan usia menarche.

\section{Data Sekunder}

Dalam penelitian ini menggunakan data sekunder yang didapat dari data siswi SMP Bina Cipta Palembang, jurnal, buku sumber dan internet yang berhubungan dengan topik penelitian.

\section{Teknik / Cara Pengumpulan Data}

Teknik pengumpulan data adalah suatu proses pendekatan kepada subjek dan proses pengumpulan karakteristik subjek yang diperlukan dalam suatu penelitian (Nursalam, 2008).

Teknik pengumpulan data pada penelitian ini menggunakan lembar kuesioner sebagai panduan dalam pengambilan data penelitian. 


\section{Populasi dan Sampel}

Populasi

Populasi adalah keseluruhan objek penelitian atau objek yang diteliti (Notoatmodjo, 2012).

Populasi pada penelitian ini adalah semua siswi kelas VII dan VIII SMP Bina Cipta Palembang yang berjumlah 79 orang (kelas VII sebanyak 44 orang dan kelas VIII sebanyak 35 orang).

\section{Sampel}

Sampel adalah sebagian yang diambil dari keseluruhan objek yang diteliti dan dianggap mewakili seluruh populasi (Notoatmodjo, 2012).

Sampel penelitian ini adalah semua siswi kelas VII dan VIII SMP Bina Cipta Palembang yang sudah mengalami menstruasi yang berjumlah 58 orang.

\section{Teknik Pengambilan Sampel}

Pengambilan sampel pada penelitian ini dilakukan dengan cara non probability sampling menggunakan metode purposive sampling yaitu pengambilan sampel didasarkan pada suatu pertimbangan tertentu yang dibuat oleh peneliti sendiri berdasarkan ciri atau sifat-sifat populasi yang sudah diketahui sebelumnya (Notoatmodjo, 2012).

Kriteria Inklusi:

1. Remaja putri kelas VII dan VIII yang sudah mengalami menstruasi.

2. Hadir pada saat dilakukan penelitian.

3. Bersedia menjadi responden dalam penelitian.

\section{HASIL PENELITIAN DAN PEMBAHASAN}

\section{Analisis Data}

Analisis Univariat

\section{Usia Menarche}

Tabel 1. Distribusi Frekuensi Responden Berdasarkan Usia Menarche di SMP Bina Cipta Palembang Tahun 2019

\begin{tabular}{llcc}
\hline No & Usia Menarche & Jumlah & $\begin{array}{c}\text { Persentase } \\
(\mathbf{\%})\end{array}$ \\
\hline 1. & Menarche Normal & 41 & 70,7 \\
2. & $\begin{array}{l}\text { Menarche Tidak } \\
\text { Normal }\end{array}$ & 17 & 29,3 \\
\hline
\end{tabular}

\begin{tabular}{rcc}
\hline Total & 58 & 100 \\
\hline
\end{tabular}

Berdasarkan Tabel 1. diatas diketahui distribusi frekuensi responden dengan usia menarche normal sebanyak 41 responden $(70,7 \%)$ lebih banyak dari pada responden dengan menarche tidak normal sebanyak 17 responden $(29,3 \%)$.

\section{Indeks Massa Tubuh (IMT)}

Tabel 2. Distribusi Frekuensi Responden Berdasarkan Indeks Massa Tubuh (IMT) di SMP Bina Cipta Palembang Tahun 2019

\begin{tabular}{llcc}
\hline No & $\begin{array}{c}\text { Indeks Massa } \\
\text { Tubuh }\end{array}$ & Jumlah & $\begin{array}{c}\text { Persentase } \\
(\mathbf{\%})\end{array}$ \\
\hline 1. & Normal & 43 & 74,1 \\
2. & Tidak Normal & 15 & 25,9 \\
\hline & Total & $\mathbf{5 8}$ & $\mathbf{1 0 0}$
\end{tabular}

Berdasarkan Tabel 2. diatas diketahui distribusi frekuensi responden dengan indeks massa tubuh kategori normal sebanyak 43 responden $(74,1 \%)$ lebih banyak dari pada responden dengan indeks massa tubuh kategori tidak normal sebanyak 15 responden $(25,9 \%)$.

\section{Konsumsi Makanan Junk Food}

Tabel 3. Distribusi Frekuensi Responden Berdasarkan Konsumsi Makanan Junk Food di SMP Bina Cipta Palembang Tahun 2019

\begin{tabular}{|c|c|c|c|}
\hline No & $\begin{array}{l}\text { Konsumsi } \\
\text { Makanan } \\
\text { Junk Food }\end{array}$ & Jumlah & $\begin{array}{c}\text { Persentase } \\
(\%)\end{array}$ \\
\hline 1. & Baik & 35 & 60,3 \\
\hline 2. & Kurang Baik & 23 & 39,7 \\
\hline & Total & 58 & 100 \\
\hline
\end{tabular}

distribusi frekuensi responden dengan konsumsi makanan junk food kategori baik sebanyak 35 responden $(60,3 \%)$ lebih banyak dari pada responden dengan konsumsi makanan junk food kategori kurang baik sebanyak 23 responden $(39,7 \%)$

\section{Analisis Bivariat}

1. Hubungan Indeks Massa Tubuh (IMT) dengan Usia Menarche Pada Siswi SMP Bina Cipta Palembang

Tabel 4. Hubungan antara Indeks Massa Tubuh (IMT) dengan Usia Menarche di SMP Bina Cipta Palembang Tahun 2019 


\begin{tabular}{|c|c|c|c|c|c|c|}
\hline \multirow{3}{*}{$\begin{array}{l}\text { Indeks Massa } \\
\text { Tubuh (IMT) }\end{array}$} & \multicolumn{4}{|c|}{ Usia Menarche } & \multirow{3}{*}{$\begin{array}{c}\mathrm{P} \\
\text { value }\end{array}$} & \multirow{3}{*}{ OR } \\
\hline & \multicolumn{2}{|c|}{ Normal } & \multicolumn{2}{|c|}{$\begin{array}{c}\text { Tidak } \\
\text { Normal }\end{array}$} & & \\
\hline & $\mathrm{n}$ & $\%$ & $\mathrm{~N}$ & $\%$ & & \\
\hline Normal & 35 & 81,4 & 8 & 18,6 & & \\
\hline $\begin{array}{l}\text { Tidak } \\
\text { Normal }\end{array}$ & 6 & 40 & 9 & 60 & 0,006 & 6,563 \\
\hline Jumlah & 41 & & 17 & & & \\
\hline
\end{tabular}

makanan junk food kurang baik terdapat 11 responden $(47,8 \%)$ yang mengalami menarche normal.

Dari hasil uji Chi-Square didapatkan nilai $P$ Value $=0,005$ hal ini menunjukkan bahwa ada hubungan konsumsi makanan junk food dengan usia menarche pada siswi SMP Bina Cipta Palembang tahun 2019. Sedangkan nilai $\mathrm{OR}=6,545$ hal ini menunjukkan bahwa remaja putri yang mengkonsumsi makanan junk food kurang baik memiliki resiko mengalami menarche tidak normal sebesar 6,545kali dibandingkan dengan remaja putri yang mengkonsumsi makanan junk food baik. Dengan demikian hipotesa awal yang menyatakan ada hubungan konsumsi makanan junk food dengan usia menarche pada siswi SMP Bina Cipta Palembang tahun 2019 terbukti secara statistik.

\section{Pembahasan}

Penelitian ini dilakukan di SMP Bina Cipta Palembang pada tanggal 4-5 April tahun 2019. Populasi yang diambil adalah semua siswi kelas VII dan VIII SMP Bina Cipta Palembang dengan jumlah sampel sebanyak 58 orang siswi yang telah mengalami menarche. Pengambilan sampel dilakukan dengan tehnik purposive sampling, yaitu pengambilan sampel didasarkan pada suatu pertimbangan tertentu yang dibuat oleh peneliti sendiri berdasarkan ciri atau sifatsifat populasi yang sudah diketahui sebelumnya. Metode pengumpulan data dengan menggunakan data primer di peroleh dari wawancara secara langsung dengan bantuan kuesioner.

\section{Hubungan Indeks Massa Tubuh (IMT) dengan Usia Menarche Pada Siswi SMP Bina Cipta Palembang}

Berdasarkan analisis univariat diketahui distribusi frekuensi responden dengan indeks massa tubuh kategori normal sebanyak 43 responden $(74,1 \%)$ lebih banyak dari pada responden dengan indeks massa tubuh kategori tidak normal sebanyak 15 responden $(25,9 \%)$.

Berdasarkan analisis bivariat diketahui dari

Berdasarkan tabel 5. diatas diketahui bahwa dari 35 responden dengan konsumsi makanan junk food baik terdapat 30 responden $(85,7 \%)$ yang mengalami menarche normal, sedangkan dari 23 responden yang dengan konsumsi 43 responden yang memiliki indeks massa tubuh (IMT) normal terdapat 35 responden $(81,4 \%)$ yang mengalami menarche normal, sedangkan dari 15 responden yang memiliki indeks massa 
tubuh (IMT) tidak normal terdapat 6 responden (40\%) yang mengalami menarche normal.

Dari hasil uji Chi-Square didapatkan nilai $P$ Value $=0,006$ hal ini menunjukkan bahwa ada hubungan Indeks Massa Tubuh (IMT) dengan usia menarche pada siswi SMP Bina Cipta Palembang tahun 2019, sedangkan nilai $\mathrm{OR}=6,563$ hal ini menunjukkan bahwa remaja putri yang memiliki Indeks Massa Tubuh (IMT) tidak normal memiliki resiko mengalami menarche tidak normal sebesar 6,563 kali dibandingkan dengan remaja putri yang memiliki Indeks Massa Tubuh (IMT) normal. Dengan demikian hipotesa awal yang menyatakan ada hubungan Indeks Massa Tubuh (IMT) dengan usia menarche pada siswi SMP Bina Cipta Palembang tahun 2019 terbukti secara statistik

Hasil penelitian ini sejalan dengan penelitian yang dilakukan Putra (2016) yang berjudul hubungan Indeks Masa Tubuh (IMT) dengan usia menarche pada siswi SMP Negeri 1 Padang. Berdasarkan hasil penelitian didapatkan bahwa sebagian besar populasi memiliki IMT pada range kategori normal $(18,5-25 \mathrm{~kg} / \mathrm{m} 2)$ yaitu sebesar $61 \%$, sedangkan $35 \%$ responden memiliki IMT pada kategori kurus, dan untuk yang gemuk sebesar 3,9. Sedangkan usia menarche terbanyak pada responden saat berumur 12 tahun, yakni sebanyak 30 orang (39\%). Responden yang mengalami menarche pada usia 9 tahun sebanyak 4 orang $(23,4 \%)$, sama dengan usia 14 tahun. Untuk responden yang menarche pada usia 10 tahun sebanyak 6 orang $(7,8 \%)$ dan usia 11 tahun sebanyak 18 orang $(23,4 \%)$. Hasil uji statistik didapatkan nilai $\mathrm{p}$ value $=0,000$ yang menunjukkan adanya hubungan yang bermakna antara Indeks Masa Tubuh (IMT) dengan usia menarche pada siswi SMP Negeri 1 Padang.

Hasil penelitian ini juga sejalan dengan penelitian Yuliastuti (2015), yang berjudul hubungan indeks masa tubuh (IMT) dengan usia menarche di SMPN 7 Banjarmasin. Hasil penelitian didapatkan dari 55 orang responden, sebagian besar memiliki indeks massa tubuh kategori normal sebanyak 35 orang $(63,6 \%)$. Sedangkan sebagian besar usia menarche responden mempunyai kategori normal yakni sebanyak 46 orang $(83,6 \%)$. Berdasarkan hasil uji statistik Chi-Square menunjukan bahwa diperoleh nilai $\mathrm{p}=0,001$ dengan $\alpha=0,05$ maka $\mathrm{p}<\alpha$ sehingga dapat diambil kesimpulan ada hubungan yang bermakna antara hubungan indeks massa tubuh dengan usia menarche.

Usia menarche dini berhubungan dengan faktor gizi karena kematangan seksual dipengaruhi oleh nutrisi dalam tubuh remaja. Remaja yang lebih dini menarche akan memiliki indeks masa tubuh (IMT) yang lebih tinggi dan remaja menarche terlambat memiliki IMT lebih kecil pada usia yang sama. Dengan terjadinya indeks masa tubuh (IMT) yang tinggi, salah satunya dapat dikarenakan kandungan lemak berlebih kemudian lemak berlebih dalam tubuh memicu peningkatan pada adypocyte-derived hormone leptin. Adypocyte-derived hormone leptin yang kemudian memicu seksresi hipotalamus untuk melepaskan gonadotropin releasing hormone $(\mathrm{GnRH})$ yang kemudian menginduksi kelenjar hipofisis anterior untuk melepaskan luteinizing hormon (LH). Luteinizing hormon (LH) yang tinggi sehingga mengawali terjadinya menarche. Apabila hormon LH lebih dini di sekresikan maka akan semakin dini terjadinya menarche pada remaja. Begitu pula sebaliknya, apabila hormon tersebut semakin lama disekresikan, maka usia menarche semakin lama datangnya (Yuliastuti, 2015).

Remaja yang memiliki status gizi tinggi akan mengalami menarche di usia yang lebih cepat dibanding mereka yang memiliki status gizi rendah, karena perbedaan jumlah kelenjar adiposa yang mereka punya menghasilkan jumlah sekresi kadar leptin yang berbeda. Mereka yang memiliki status gizi tinggi atau di atas normal akan mendapat menarche di usia yang terlalu cepat, sedangkan mereka yang memiliki status gizi rendah atau di bawah normal mengalami menarche di usia yang terlalu lambat. Lalu, mereka dengan status gizi yang normal mengalami menarche di usia yang juga normal (Sylvia, 2012).

Makanan yang bergizi tinggi dan berlemak tinggi dari hewani akan mengakibatkan pertumbuhan berat badan pada perempuan remaja. Kadar estrogen akan meningkat akibat kolestrol tinggi. Suatu hal yang dapat mempengaruhi pembentukan hormon salah satunya adalah asupan gizi, dengan asupan gizi yang baik dapat mempercepat pembentukan hormon-hormon yang mempengaruhi datangnya menarche, sehingga dengan perbaikan gizi atau asupan gizi yang baik dapat menyebabkan umur 
haid pertama menjadi lebih dini. Kekurangan dan kelebihan gizi pada seseorang akan berdampak pada penurunan fungsi reproduksi (Diaris, 2017).

Indeks Massa Tubuh telah diketahui sebagai salah satu faktor yang dapat mempengaruhi usia menarche.IMT yang baik menunjukkan pemenuhan nutrisi yang optimal. Nutrisi yang optimal dapat membantu mempercepat pertumbuhan dan perkembangan organ seksual, sedangkan tidak terpenuhinya nutrisi dapat berakibat terlambatnya pematangan seksual dan hambatan pertumbuhan. Pola konsumsi lemak yang tinggi juga secara tidak langsung dapat mempengaruhi usia menarche. Lemak akan diubah menjadi kolesterol di dalam tubuh dan merupakan bahan bakar utama dalam pembentukan hormon estrogen dan progesteron. Demikian juga dengan aktivitas fisik yang dilakukan secara rutin dan teratur setiap minggu. Aktivitas fisik dapat meningkatkan massa otot dibandingkan massa timbunan lemak, sehingga meskipun berat badan bertambah, tidak akan memberikan pengaruh kepada peningkatan persentase lemak tubuh dan mengurangi jumlah jaringan lemak yang berguna untuk menghasilkan leptin dan menginisiasi menarche (Putra, 2016).

Dari sebuah penelitian yang dilakukan oleh Shalisha (2011) di Tanjung Morawa, didapatkan bahwa semakin baik status gizi seseorang, maka usiamenarche orang tersebut akan semakin tepat (tidak terlambat atau terlalu dini).

Dalam penelitiannya, Aishah (2011) mengungkapkan bahwa remaja yang memiliki IMT yang lebih tinggi cenderung mendapatkan menstruasi pertamanya terlebih dahulu, karena kadar leptin yang disekresikan oleh kelenjara diposa. Boenga (2011) mengatakan bahwa leptin mempengaruhi kadar neuropeptida yang memengaruhi GnRH. Lalu, berubahnya kadar GnRH yang disekresikan juga mengubah kadar sekresi LH. Selain itu, leptin berpengaruh pada maturasi oosit yang merangsang pematangan ovum yang dihasilkan oleh ovarium.Maka dapatdisimpulkan bahwa remaja yang memiliki status gizi tinggi akan mengalami menarche di usia yang lebih cepat dibanding mereka yang memiliki status gizi rendah, karena perbedaan jumlah kelenjar adiposa yang mereka punya menghasilkan jumlah sekresi kadar leptin yang berbeda. Mereka yang memiliki status gizi tinggi atau di atas normal akan mendapat menarche di usia yang terlalu cepat, sedangkan mereka yang memiliki status gizi rendah atau di bawah normal mengalami menarche di usia yang terlalu lambat. Lalu, mereka dengan status gizi yang normal mengalami menarche di usia yang juga normal.

Berdasarkan hasil penelitian dan pembahasan diatas peneliti berasumsi bahwa indeks massa tubuh (IMT) berhubungan dengan usia menarche. Semakin tinggi Indeks Massa Tubuh (IMT) seseorang maka akan semakin cepat mengalami menarche. Sebaliknya semakin rendah IMT seseorang maka akan mengalami usia menarche yang lambat dan mereka dengan status gizi yang normal mengalami menarche di usia yang juga normal. Hal ini karena perbedaan jumlah kelenjar adiposa yang mereka punya menghasilkan jumlah sekresi kadar leptin yang berbeda. Selain itu karena kandungan lemak yang berlebih dalam tubuh sehingga memicu peningkatan pada adypocyte-derived hormone leptin.

\section{Hubungan Konsumsi Makanan Junk Food dengan Usia Menarche Pada Siswi SMP Bina Cipta Palembang}

Berdasarkan analisis univariat diketahui distribusi frekuensi responden dengan konsumsi makanan junk food kategori baik sebanyak 35 responden $(60,3 \%)$ lebih banyak dari pada responden dengan konsumsi makanan junk food kategori kurang baik sebanyak 23 responden $(39,7 \%)$.

Berdasarkan analisis bivariat diketahui bahwa dari 35 responden dengan konsumsi makanan junk food baik terdapat 30 responden $(85,7 \%)$ yang mengalami menarche normal, sedangkan dari 23 responden yang dengan konsumsi makanan junk food kurang baik terdapat 11 responden $(47,8 \%)$ yang mengalami menarche normal.

Dari hasil uji Chi-Square didapatkan nilai $P$ Value $=0,005$ hal ini menunjukkan bahwa ada hubungan konsumsi makanan junk food dengan usia menarche pada siswi SMP Bina Cipta Palembang tahun 2018. Sedangkan nilai $\mathrm{OR}=6,545$ hal ini menunjukkan bahwa remaja putri yang mengkonsumsi makanan junk food kurang baik memiliki resiko mengalami menarche tidak normal sebesar 6,545 kali dibandingkan dengan remaja putri yang 
mengkonsumsi makanan junk food baik. Dengan demikian hipotesa awal yang menyatakan ada hubungan konsumsi makanan junk food dengan usia menarche pada siswi SMP Bina Cipta Palembang tahun 2019 terbukti secara statistik.

Hasil penelitian ini sejalan dengan penelitian Zalni (2017) yang berjudul hubungan status gizi, konsumsi makanan dan aktivitas fisik dengan usia menarche di seluruh SD Negeri di Kecamatan Marpoyan Damai, Pekanbaru. Hasil analisis univariat menunjukkan bahwa rata-rata usia menarche anak adalah 11,9 $\pm 0,8$ tahun dengan usia terendah 9,7 tahun dan tertinggi 14,6 tahun. Terdapat 3 orang anak $(2,7 \%)$ dengan menarche dini. Menarche dini adalah menstruasi yang datangnya lebih awal yaitu di bawah usia 11 tahun. Frekuensi konsumsi junk food anak termasuk cukup sering dalam satu minggu yaitu lebih dari 1 kali dalam sehari. Jenis junk food yang banyak dikonsumsi anak dari 10 jenis junk food adalah gorengan $(32,5 \%)$, mie instan $(23,5 \%)$, dan kentang goreng $(12,5 \%)$. Hasil uji statistik didapatkan nilai $\mathrm{p}$ value $=0,013$ yang artinya ada hubungan antara konsumsi makanan junk food dengan usia menarche.

Hasil penelitian ini juga sejalan dengan penelitian Wulansari (2012) yang berjudul hubungan konsumsi junk food dan media informasi terhadap menarche dini pada siswi sekolah dasar di Surakarta. Hasil penelitian didapatkan usia menarche dini responden menunjukkan bahwa umur terendah adalah 9 tahun, umur tertinggi 10 tahun, rata-rata umur 9,8 tahun dan standar deviasi adalah 0,4. Sedangkan bila ditinjau dari distribusi frekuensi umur menarche, maka distribusi tertinggi adalah usia 10 tahun yaitu sebanyak 25 responden $(81 \%)$ dan sisanya 6 responden (19\%) mengalami menarche pada usia 9 tahun. Distribusi konsumsi junk food menunjukkan distribusi tertinggi responden dalam kategori sering yaitu sebanyak 18 responden $(60 \%)$ dengan skor 20-34 kali dan sisanya 12 responden $(40 \%)$ memiliki pola konsumsi junk food dengan skor. Hasil uji korelasi Rank Spearman hubungan pola makan dengan usia menarche dini diperoleh nilai pvalue 0,005 sehingga dapat disimpulkan bahwa terdapat hubungan pola makan dengan usia menarche dini pada siswi sekolah dasar di Surakarta.
Kebiasaan makan fast food yang berlebih dapat mengakibatkan obesitas pada anak. Obesitas mempengaruhi tingkat kesuburan seorang perempuan sehingga anak yang mengalami obesitas kematangan seksualnya ditemukan lebih cepat meliputi pertumbuhan payudara, menarche, pertumbuhan rambut pubis serta aksila lebih cepat. Kebiasaan makan fast food merupakan perilaku seseorang dalam memenuhi kebutuhan makan sehari-hari, berupa konsumsi makanan meliputi jenis dan frekwensi asupan makanan yang berkalori tinggi seperti : pizza, fried chicken, kentang goreng, es kream dan aneka makanan mie. Konsumsi makanan fast food dikatakan baik jika frekwensinya 1 kali dalam seminggu, jika lebih dari itu dikatakan kurang baik karena berdampak pada kesehatan tubuh (Soetjiningsih dalam Maidartati, 2013).

Usia menarche anak yang sering mengonsumsi junk food akan lebih cepat 0,3 tahun dibanding dengan anak yang jarang mengonsumsi junk food. Makanan ini banyak mengandung kadar lemak dan garam yang tinggi. Minuman yang tersedia pada restoran siap saji seperti minuman ringan (soft drink) juga menambah masukan kalori berlebih pada remaja. Remaja yang sering mengonsumsi makanan junk food cenderung mengalami kelebihan berat badan (Zalni, 2017).

Hasil penelitian ini sejalan dengan pernyataan Path dalam Putri (2013) bahwa konsumsi soft drink yang mengandung pemanis buatan cenderung meningkat selama fase luteal (masa saat ovulasi terjadi sampai terjadinya menstruasi). Sehingga selama fase luteal terjadi peningkatan asupan makanan atau energi. Menurut (Susanti, 2012) makanan fast food banyak mengandung pemanis buatan, lemak, dan zat aditif bisa menyebabkan menarche lebih awal.

Sejalan dengan teori yang di kemukakan oleh Wulansari (2015), yang menyatakan bahwa konsumsi junk food pada remaja berpengaruh terhadap peningkatan gizi remaja. Umumnya makanan cepat saji umumnya mengandung kalori, kadar lemak, gula dan sodium $(\mathrm{Na})$ yang tinggi tetapi rendah serat, vitamin $\mathrm{A}$, asam akorbat, kalsium dan folat. Remaja putri dengan kelebihan nutrisi (kelebihan lemak dan berat badan), menarche juga terjadi lebih dini. Nutrisi mempunyai pengaruh terhadap kematangan seksual manusia, karena gizi mempengaruhi 
sekresi hormon gonadotropin dan respon terhadap Luteinizing Hormone (LH), hormon ini berfungsi untuk sekresi estrogen dan progesteron dalam ovarium sehingga tanda-tanda seks sekunder akan cepat muncul dibanding remaja putri yang kekurangan nutrisi. Kegagalan mengkonsumsi gizi adekuat selama remaja menyebabkan kematangan seksual terlambat dan pertumbuhan mengalami keterlambatan atau terhenti.

Berdasarkan hasil penelitian dan pembahasan diatas peneliti berasumsi bahwa mengkonsumsi junk food berlebihan dapat berhubungan dengan menarche dini pada remaja putri. Hal ini karena makanan junk food banyak mengandung kalori yang tinggi yang tidak baik untuk tubuh sehingga dapat menyebabkan obesitas. Anak yang mengalamai obesitas cenderung akan mengalami pertumbuhan anggota tubuh yang lebih cepat dibandingkan dengan anak normal seusianya.

\section{Keterbatasan Penelitian}

Dalam pelaksanaan penelitian ini, tidak terlepas dari keterbatasan-keterbatasan yang terjadi serta kemungkinan yang tidak dapat dihindari walaupun telah diupayakan untuk mengatasinya. Peneliti menyadari kurangnya pengalaman dalam melakukan penelitian tentu hasilnya kurang sempurna dan banyak kekurangan. Keterbatasan dalam penelitian ini diantaranya :

1. Keterbatasan waktu dan biaya sehingga penelitian ini hanya mengambil beberapa responden untuk dijadikan sampel dalam penelitian.

2. Responden tidak dapat dikumpulkan secara bersamaan karena harus menunggu jam pelajaran kosong.

\section{KESIMPULAN}

Berdasarkan hasil penelitian yang telah dilakukan terhadap siswa kelas VII dan VIII SMP Bina Cipta Palembang yang dilakukan pada tanggal 4-5 April 2019, dapat disimpulkan sebagai berikut:

1. Ada hubungan Indeks Massa Tubuh (IMT) dengan usia menarche pada siswi SMP Bina Cipta Palembang tahun 2019, dengan nilai $p$ value $0,006<\alpha(0,05)$ dan $\mathrm{OR}=6,563$.

2. Ada hubungan konsumsi makanan junk food dengan usia menarche pada siswi SMP Bina
Cipta Palembang tahun 2019, dengan nilai $p$ value $0,005<\alpha(0,05)$ dan $\mathrm{OR}=6,545$.

\section{SARAN}

\section{Bagi SMP Bina Cipta Palembang}

Agar pihak sekolah dapat memberikan lebih banyak informasi untuk meningkatkan pengetahuan siswi tentang menarche serta memperbanyak melaksanakan kegiatan penyuluhan dengan mendatangkan narasumber baik dokter, tenaga kesehatan maupun psikolog untuk berdiskusi tentang kesehatan reproduksi khususnya masalah menarche.

\section{Bagi Stikes Mitra Adiguna Palembang}

Diharapkan pihak pendidikan dapat melengkapi sumber-sumber bacaan di perpustakaan khususnya tentang Indeks Massa Tubuh (IMT) dan konsumsi makanan junk food terhadap usia menarche sebagai penunjang dosen dan mahasiswa dalam melakukan penelitian selanjutnya.

\section{Bagi Peneliti Selanjutnya}

Diharapkan peneliti selanjutnya dapat melakukan penelitian dengan menggunakan variabel lain yang berbeda dan dengan menggunakan metode penelitian kualitatif, sehingga penelitian tentang usia menarche dapat lebih bervariasi.

\section{DAFTAR PUSTAKA}

Aisyah, Megawati. 2016. Hubungan Riwayat Menonton Media Dewasa Teman Menonton Media Dewasa dan Perilaku Seksual dengan Kejadian Menarche

Anwar, Muhamad. 2011. Ilmu Kandungan Edisi Ketiga. Jakarta : PT Bina Pustaka Sarwono Prawirohardjo

Diaris, Ni Made. 2017. Hubungan Status Gizi Dengan Usia Menarche Pada Siswi Di SMP N 2 Ungaran Kabupaten Semarang

Dinkes Kota Palembang. 2016. Profil Kesehatan Kota Palembang.http://www.dinkes.go.id, diakses 20 Februari 2018

Fuadah, Fahmi. 2016. Hubungan Antara Status Gizi Dengan Usia Menarche Dini pada Remaja Putri di SMP Umi Kulsum 
Banjaran Kab. Bandung Provinsi Jawa Barat Tahun 2016. Jurnal Ilmu Kesehatan Volume 10, Nomor 2, Desember 2016 ISSN 1410

Hardianingsih,, Dani. 2017. Tingkat kecemasan remaja menghadapi perubahan fisik masa pubertas pada siswi MTS Pondok Pesantren As- salafiyah Yogyakarta

Indaryani. 2010. Hubungan awitan pubertas dan status sosial ekonomi serta status gizi pada anak perempuan.

Irianto, Koes. 2014. Biologi reproduksi. Bandung : Alfabeta

Irianto, Koes. 2015. Kesehatan Reproduksi. Bandung : Alfabeta.

Kemenkes RI. 2017. Profil kesehatan Indonesia tahun 2016. http://www.kemenkes.go.id, diakses 20 Februari 2018

Kusmiran, Eny. 2012. Kesehatan reproduksi remaja dan wanita. Jakarta : Salemba Medika.

Maidartati. 2013. Hubungan Konsumsi Makanan Fast Food Dan Aktivitas Fisik Dengan Kejadian Menarche Pada Anak (9 - 12 Tahun) Di Sekolah Dasar Banjarsari II Bandung

Notoatmodjo, Soekidjo. 2012. Metode penelitian kesehatan. Jakarta : Rineka Cipta.

Puspitasari, Ratna. 2016. Gambaran Usia Menarche Dini Di Pada Anak Sekolah Dasar Di Daerah Urban. Jurnal Volume 4, Nomor 4, Oktober 2016

Putra, Rahmad Nurul Yuda. 2016. Hubungan Indeks Massa Tubuh (IMT) Dengan Usia Menarche Pada Siswi SMP Negeri 1 Padang. Jurnal Kesehatan Andalas.

Putri. 2013. Analisis faktor hubungan usia menarche dini.Jurnal Fakultas Kesehatan Masyarakat Universitas Airlangga

SMP Bina Cipta Palembang. 2017. Data Siswa tahun ajaran 2017-2018
Sugiono. 2016. Metode Penelitian Kuantitatif Kualitatif dan $R \& D$. Bandung: Alfabeta

Sylvia. 2012. Hubungan Status Gizi dengan Usia Menarche pada Remaja Putri di SMP Negeri 22 Bandar Lampung. Jurnal Majority (Medical Journal of Lampung University)

Tedjo. 2012. Indeks massa tubuh.https://tedjho.wordpress.com/2012/09 /21/215, diakses 20 Februari 2018

Wulansari. 2012. Hubungan Konsumsi Junk Food Dan Media Informasi Terhadap Menarche Dini Pada Siswi Sekolah Dasar Di Surakarta

Yuliastuti, Erni. 2015. Hubungan indeks masa tubuh (IMT) dengan usia menarche di SMPN 7 Banjarmasin

Zalni, Rummy Islami. 2017. Usia Menarche Berhubungan Dengan Status Gizi, Konsumsi Makanan Dan Aktivitas Fisik. Jurnal Kesehatan Reproduksi, 8(2), 2017 